\title{
SENDO APOIADA DURANTE A HOSPITALIZAÇÃO
}

\author{
Cinthia Reis Almeida ${ }^{1}$; Evanilda Souza de Santana Carvalho ${ }^{2}$ Luciano Marques dos \\ Santos $^{3}$; Bruna Brandão da Silva ${ }^{4}$. \\ 1. Bolsista FABESB, Graduanda em Enfermagem, Universidade Estadual de Feira de Santana, email: \\ cinthiialmeida@gmail.com \\ 2. Orientadora, Departamento de Saúde, Universidade Estadual de Feira de Santana, email: \\ evasscarvalho@yahoo.com.br \\ 3. Núcleo Interdisciplinar de Estudos sobre Desigualdades em Saúde, Departamento de Saúde, Universidade Estadual \\ de Feira de Santana, e-mail: lucmarxenfo@yahoo.com.br \\ 4. Núcleo Interdisciplinar de Estudos sobre Desigualdades em Saúde, Departamento de Saúde, Universidade Estadual \\ de Feira de Santana, e-mail: brunabrandao_1@ hotmail.com
}

PALAVRAS-CHAVES: Recém-nascido prematuro; Unidade de Terapia Intensiva Neonatal; Famílias.

\section{INTRODUÇÃO}

O nascimento de um recém-nascido prematuro (RNPT), com consequente hospitalização em Unidades de Terapia Intensiva Neonatal (UTIN), por ser algo imprevisto, se torna um acontecimento intempestivo, que traz alterações na estrutura familiar, ocasionando situações de crise para todos os envolvidos, mas, sobretudo para a mãe (SOUZA et al., 2011).

Isso porque, durante a gestação, a mulher e seus familiares criam expectativas sobre o futuro do recém-nascido, planejando e se preparando para sua chegada (SANTOS et al., 2013). Assim, quando ocorre um nascimento prematuro, as idealizações antes sonhadas se transformam em angústias e incertezas na família (ALMEIDA; SILVA; VIEIRA, 2010).

A UTIN é vista por muitas destas mulheres como estranho e assustador, sendo difícil a vivência neste espaço hospitalar, já que o próprio espaço com os aparatos tecnológicos a fazem temer diante da vida dos seus filhos (SANTOS et al., 2013).

Por outro lado, as visitas diárias ao filho na UTIN, a convivência com a equipe e a visualização das tecnologias utilizadas por eles, faz com que as mães passem a reconhecer a UTIN como o lugar destinado ao cuidado do RNPT, mudando as representações negativas sobre esta unidade (SANTOS et al., 2013).

Sendo assim, apesar das mães desenvolverem muitos sentimentos negativos ao longo da experiência, surgem também sentimentos que as mantêm fortalecidas, encorajadas e confiantes quanto à recuperação do filho. Elas passam a acreditar na recuperação do RNPT e em levá-lo para casa (SOUZA et al., 2011).

Dessa forma, é de suma importância o apoio oferecido às mães durante a hospitalização do RNPT que surge como condição que permite as mesmas gerirem as dificuldades e desafios que acontecem durante esse período.

Em seu estudo Chang Lee, Long e Boore (2009), encontraram quatro principais fontes de apoio relatadas pelas mães: os profissionais de saúde; os membros da família; outros pais na UTIN; e as crenças religiosas ou espirituais, que fortalecem, cada um a sua maneira, a mãe a enfrentar essa situação.

A finalidade em estudar sobre tal assunto relaciona-se com o aumento constante do número de nascimentos prematuros e com eles da maternidade prematura. Assim, entendendo que as mães não estão preparadas para vivenciar essa nova realidade, nem tão pouco de acompanhar o RNPT durante a hospitalização na UTIN, faz-se necessário compreender como essas mães vivenciam essa nova experiência e quais as formas de apoio que necessitam e lhes são oferecidas nesse processo.

Isto posto, questionou-se: como a mãe experiencia a hospitalização dos recémnascidos prematuros durante a hospitalização na UTIN? Para investigar essa problemática, 
este estudo teve como objetivo geral: Compreender a experiência materna diante da hospitalização do recém-nascido prematuro na Unidade de Terapia Intensiva Neonatal de dois hospitais públicos da cidade de Feira de Santana-Bahia.

Como objetivos específicos: Identificar os sentimentos maternos vivenciados durante a hospitalização dos recém-nascidos prematuros hospitalizados na UTIN e descrever a estrutura, a rede de apoio e o suporte social recebido pelas mães de recém-nascidos prematuros hospitalizados na UTIN.

\section{METODOLOGIA}

Este estudo foi do tipo qualitativo, descritivo e exploratório, vinculado à pesquisa multicêntrica "Parto prematuro: estudo dos fatores associados para construção de estratégias de prevenção".

Teve como campo de pesquisa dois hospitais do município de Feira de Santana, no interior da Bahia. As participantes do estudo foram mulheres que tiveram parto prematuro, ou seja, que tiveram seu filho com menos de 37 semanas.

Foram adotados como critérios de inclusão: puérperas que tiveram parto entre 20 e 36 semanas e 6 dias de gestação e o concepto pesando mais que 500 gramas; ter o RNPT hospitalizado na UTIN; ter acompanhado a hospitalização do RNPT na UTIN; não apresentar problemas clínicos e obstétricos; ter condições psicológicas para as entrevistas.

Foi entregue as entrevistadas o Termo de Consentimento Livre e Esclarecido (TCLE). O documento foi assinado pelo pesquisador (a) e pelas participantes, ficando uma cópia com a participante e outra com o pesquisador (a).

As informações fornecidas pelas participantes permaneceram confidenciais e o anonimato das mesmas foi mantido através do uso códigos: (E01, E02, E03), sendo "E" referente à entrevista e 01,02 , etc., com a quantidade e ordem das entrevistas realizadas.

Foram entrevistadas as puérperas que tiveram parto prematuro no período de julho a novembro de 2015, totalizando dez mulheres, sendo adotado como critério para o encerramento da coleta a saturação teórica dos mesmos. Foi utilizado um roteiro de entrevista semiestruturada, onde as participantes foram estimuladas a responder algumas questões norteadoras.

A análise dos dados foi realizada de acordo com o método de análise temática preconizada por Bardin (2011), onde o tema é o conceito central. Deste modo, as entrevistas foram transcritas na íntegra, lidas atentamente, em seguida recortou-se e agrupou as falas (unidades de análise) convergentes para formar as unidades de significados e as categorias temáticas.

Este estudo atendeu, em todas suas etapas, os princípios éticos que envolvem as pesquisas com seres humanos, respeitando as normas da resolução $n^{\circ} 466 / 2012$, do Conselho Nacional de Saúde.

Este projeto de pesquisa foi aprovado pelo Comitê de Ética e Pesquisa da Universidade Federal do Rio Grande (FURG) através do Parecer de número 134/2013 e da Universidade Estadual de Feira de Santana (UEFS), através do Parecer de número 643.668.

\section{RESULTADOS E DISCUSSÕES}

Após a análise dos dados emergiram três categorias: Recebendo apoio de familiares; Recebendo apoio da equipe; Recebendo apoio de outras puérperas.

A primeira categoria Recebendo apoio de familiares abordou sobre o apoio dado pela família às mães, que se mostrou fundamental para auxiliá-las a enfrentar essa situação, pois o simples fato de estar perto, mostrar-se preocupado, renovam as forças e deixam a mãe mais segura, sabendo que terá ajuda sempre que precisar e a quem poderá recorrer. 
Resultados similares foram encontrados no estudo de Gomes et al. (2011), no qual o apoio dos familiares configurou-se como uma fonte de força e energia à mãe. Pois, durante as visitas, a mãe desabafa seus medos e angústias, bem como vivencia alguns momentos de prazer e de relaxamento, deixando de lado, suas preocupações e angústias.

Já a segunda categoria Recebendo apoio da equipe mostrou que a equipe de saúde envolvida nos cuidados com o prematuro torna-se uma fonte de apoio, quando além de cumprir seu papel profissional de assistir o RNPT, estende sua assistência para além da clínica, preocupando-se em dar um suporte emocional a mãe.

Esses achados corroboram com o estudo de Anjos et al. (2012), no qual a equipe era vista pelas mães como uma forma de amparo, além de aliviar as tensões e ansiedade e gerar sentimentos bons, de esperança, conforto e confiança.

A terceira categoria Recebendo apoio de outras puérperas apontou que o convívio com outras puérperas que estão vivenciando a mesma situação possibilita a mãe uma ajuda mútua para enfrentar essa situação.

No estudo de Araújo e Rodrigues (2010) evidenciou-se, nos relatos das entrevistadas, que no processo de hospitalização há a necessidade de apoio, ajuda e de compartilhamento de experiências. Desse modo, as outras mães que estão vivenciando a mesma situação passam a cuidar umas das outras, numa relação recíproca de solidariedade.

\section{CONCLUSÃO}

Percebeu-se que durante a hospitalização do RNPT na UTIN a mãe necessita de apoio para auxiliá-las a enfrentarem essa situação difícil, na qual se encontram vulneráveis e carentes.

Assim, os familiares, a equipe de saúde envolvida nos cuidados com o prematuro e as outras puérperas inseridas no mesmo contexto, todos, dentro das suas particularidades, fortalecem e encorajam as mães e renovam a esperança de que dias melhores virão e que o tão sonhado retorno para casa está cada vez mais próximo.

Desse modo, ressalta-se nessa pesquisa, a importância de preparar previamente a mãe para o ambiente da UTIN, explicando os aparatos tecnológicos inerentes ao local, além de deixar claro o que ela pode ou não fazer com relação ao seu filho, mostrando sempre a importância da sua presença para recuperação do mesmo, bem como da sua família.

Ademais, destaca-se a importância do cuidado centrado na família, ou seja, a necessidade de incluir a família no contexto de hospitalização do RNPT, acolhendo-a em todas as demandas do cuidado, fazendo-a perceber que também é sujeito ativo nesse processo, podendo contribuir na recuperação do prematuro.

\section{REFERÊNCIAS}

ALMEIDA, A. K.A.; SILVA, D. B.; VIEIRA. A. C B. Percepção dos pais em relação ao atendimento do RN prematuro em UTI neonatal do Hospital Materno Infantil de GoiâniaGO. Revista de Trabalhos Acadêmicos, n.2, 2010.

ANJOS, L. S. et al. Percepções maternas sobre o nascimento de um filho prematuro e cuidados após a alta. Rev Bras Enferm, v. 65, n. 4, p. 571-7, Brasília, 2012.

ARAUJO, B. B. M.; RODRIGUES, B. M. R. D. Vivências e perspectivas maternas na internação do filho prematuro em Unidade de Tratamento Intensivo Neonatal. Rev Esc Enferm USP, v. 44, n. 4, p. 865-72, 2010.

BARDIN, L. Análise de conteúdo. Trad. Luis Antero Reto, Augusto Pinheiro. São Paulo: Edições 70, 2011. 
CHANG LEE, S. N.; LONG, A.; BOORE, J. Taiwanese women's experiences of becoming a mother to a very-low-birth-weight preterm infant: A grounded theory study. International Journal of Nursing Studies, v. 46, p. 326-336, 2009.

GOMES, G. C. et al. O apoio social ao familiar cuidador durante a internação hospitalar da criança. Rev enferm UERJ, Rio de Janeiro, v. 19, n. 1, p. 64-69, 2011.

SOUZA, A. M. et al. Sentimentos expressos por mães de neonatos prematuros internados na uti neonatal. Cuid. Fundam. Online, p. 100-10, dez, 2011.

SANTOS, L. M. dos et al. Vivências de mães de recém-nascidos prematuros na unidade de terapia intensiva neonatal. Rev. Soc. Bras. Enferm. Ped,v.13, n.2, p 73-81, 2013. 